\title{
Separate Sensible and Latent Cooling System: A Preliminary Analysis of a Novel Approach
}

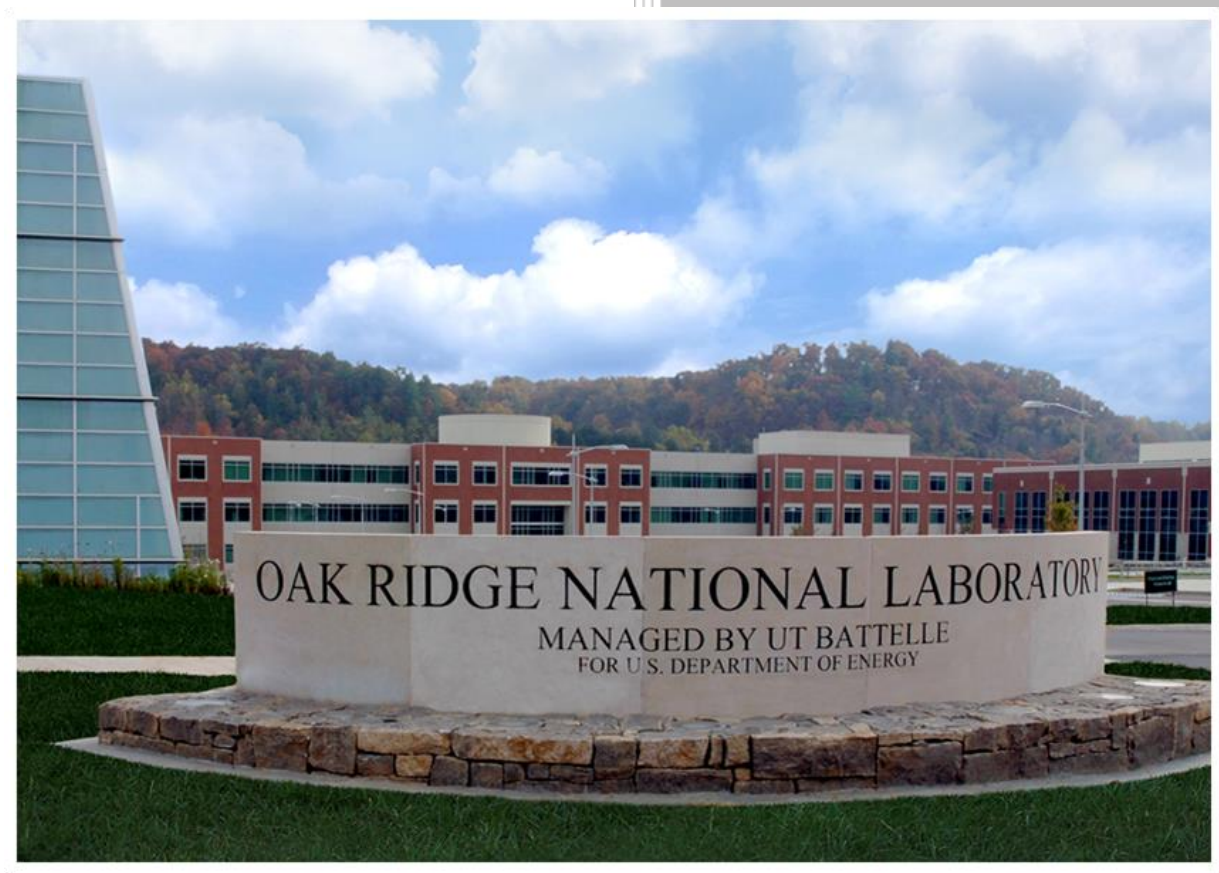

Approved for public release. Distribution is unlimited

Kashif Nawaz

Omar Abdelaziz

August 31, 2017 


\section{DOCUMENT AVAILABILITY}

Reports produced after January 1, 1996, are generally available free via US Department of Energy (DOE) SciTech Connect.

Website http://www.osti.gov/scitech/

Reports produced before January 1, 1996, may be purchased by members of the public from the following source:

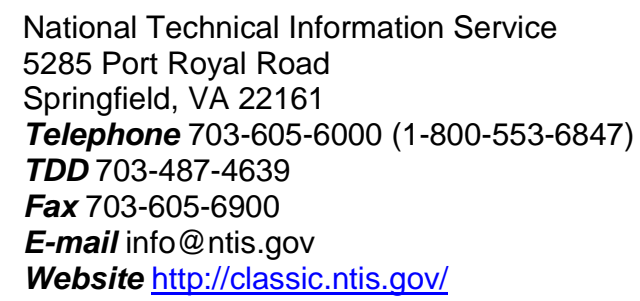

Reports are available to DOE employees, DOE contractors, Energy Technology Data Exchange representatives, and International Nuclear Information System representatives from the following source:

Office of Scientific and Technical Information

PO Box 62

Oak Ridge, TN 37831

Telephone 865-576-8401

Fax 865-576-5728

E-mail reports@osti.gov

Website http://www.osti.gov/contact.html

This report was prepared as an account of work sponsored by an agency of the United States Government. Neither the United States Government nor any agency thereof, nor any of their employees, makes any warranty, express or implied, or assumes any legal liability or responsibility for the accuracy, completeness, or usefulness of any information, apparatus, product, or process disclosed, or represents that its use would not infringe privately owned rights. Reference herein to any specific commercial product, process, or service by trade name, trademark, manufacturer, or otherwise, does not necessarily constitute or imply its endorsement, recommendation, or favoring by the United States Government or any agency thereof. The views and opinions of authors expressed herein do not necessarily state or reflect those of the United States Government or any agency thereof. 
ORNL/TM-2017/479

Energy and Transportation Sciences Division

\section{SEPARATE SENSIBLE AND LATENT COOLING SYSTEM: A PRELIMINARY ANALYSIS OF A NOVEL APPROACH}

Authors:

Kashif Nawaz

Omar Abdelaziz

Date Published: 08-31-2017

Prepared by

OAK RIDGE NATIONAL LABORATORY

Oak Ridge, TN 37831-6283

managed by

UT-BATTELLE, LLC

for the

US DEPARTMENT OF ENERGY

under contract DE-AC05-00OR22725 



\section{CONTENTS}

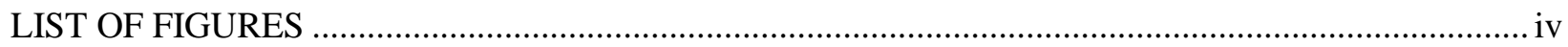

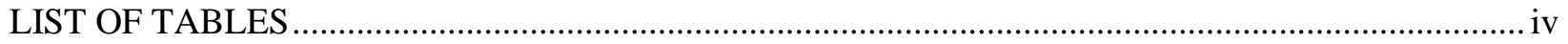

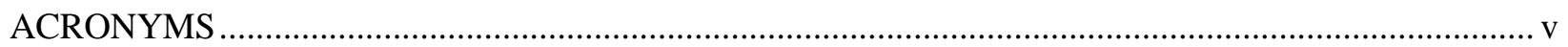

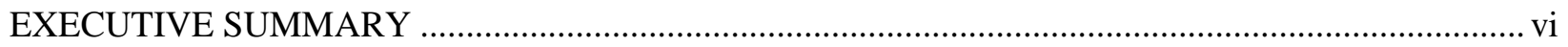

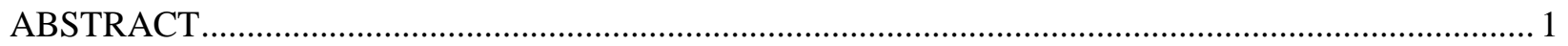

1. SIGNIFICANCE OF SEPARATE SENSIBLE AND LATENT COOLING SYSTEMS ................... 1

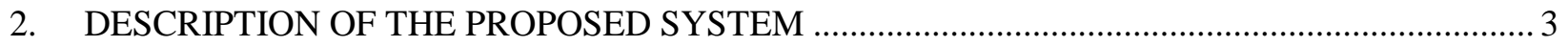

3. FEASIBILITY ANALYSIS FOR PROPOSED SYSTEM …..................................................... 5

3.1 DEVELOPMENT OF METAL FOAM HEAT EXCHANGERS ……................................ 5

3.2 EXISTING KNOWLEDGE ABOUT THE PERFORMANCE OF MFHXs............................ 6

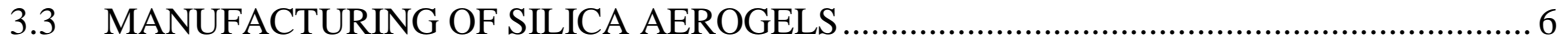

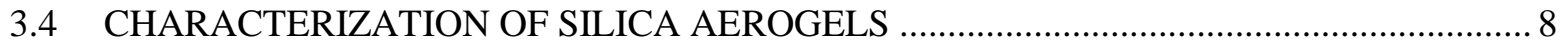

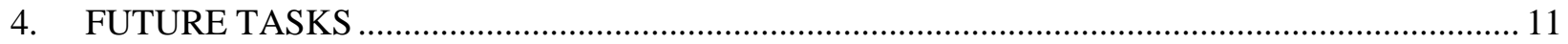

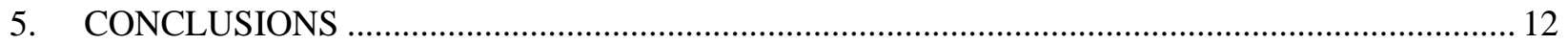

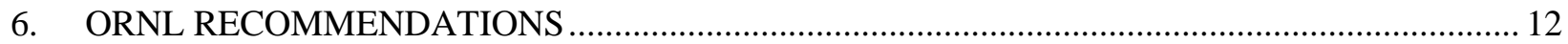

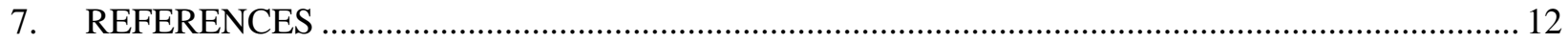




\section{LIST OF FIGURES}

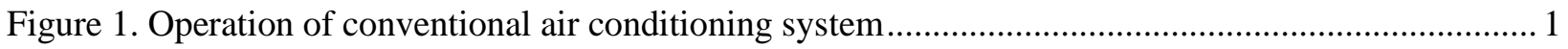

Figure 2. Operation of SSLC system (with enthalpy wheel) …....................................................... 2

Figure 3. A close-up view of a 10 PPI metal foam cell ............................................................... 3

Figure 4. Surface area per unit volume for different metal foams (ERG Aerospace Materials).................. 4

Figure 5. A configuration for a desiccant-coated metal foam dehumidification device ............................. 5

Figure 6. Metal foam heat exchanger (constructed in-house) ................................................................. 5

Figure 7. Thermal-hydraulic performance of metal foam heat exchangers under dry operating conditions

Figure 8. Microstructure of silica aerogel prepared by sol-gel process ................................................... 7

Figure 9. SEM images of silica aerogel coated metal foam ligaments dried (a) by evaporation (b) supercritically $\left(\mathrm{CO}_{2}\right)$

Figure 10. Manufacturing of silica aerogels (adapted from Brinker and Scherer 1990)........................... 8

Figure 11. Nitrogen adsorption/desorption for silica aerogels ........................................................ 9

Figure 12. Nitrogen adsorption/desorption for Zeolite 13X ............................................................... 9

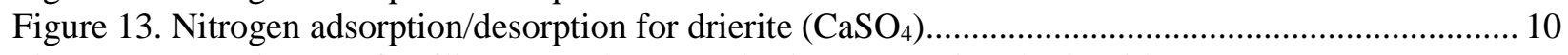

Figure 14. SEM image of a silica aerogel prepared using ammonium hydroxide ................................... 11

Figure 15. SEM image of a silica aerogel prepared using hydrofluoric acid .......................................... 11

\section{LIST OF TABLES}

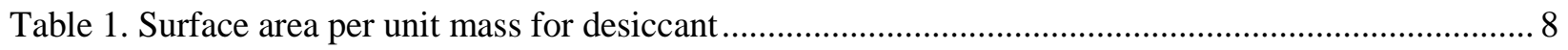




\section{ACRONYMS}

BET Brunauer, Emmett and Teller

DVS dynamic vapor sorption

MFHX metal foam heat exchanger

SEM scanning electron microscopy

SSLC Separate sensible and latent cooling

TGA thermal gravimetric analysis 


\section{EXECUTIVE SUMMARY}

Dehumidification accounts for about $40 \%$ of the energy consumed by residential and commercial buildings (ASHRAE 2017). Compared with conventional single vapor-compression systems, separate sensible and latent cooling systems have shown significant benefits due to their noticeable reduction in energy consumption (Hwang et al. 2010). This report presents a feasibility analysis for a novel dehumidification approach. Open cell metal foams are considered as substrate materials for a desiccant coated on the surface.

Three different aspects are considered for the preliminary feasibility analysis:

1. Preparation of desiccants: A full understanding of the preparation of silica aerogel by the sol-gel process is an important aspect of the proposed study. As the goal is to coat the substrate metal foam, it is important to prepare the desiccants from scratch to ensure a uniform coating. Additionally, doing so helps to ensure that all of the desiccants have the same composition and characteristics.

2. Characterization of desiccants: BET surface area measurement and gas adsorption/desorption analysis is important to understand the overall behavior of the material for the proposed application. Although such experiments were conducted using nitrogen, the outcome in terms of surface area per gram is critical to establish the performance of desiccants. Scanning electron microscopy was conducted to investigate the impact of the catalyst on the microstructure of the aerogel.

3. Preparation of metal foam heat exchangers: Metal foal has good mechanical properties, but machining the foam was a challenge. During the study, multiple samples were manufactured using conventional tooling to demonstrate the feasibility of the proposed technology.

Based on the successful completion of these three tasks, future activities are planned with the final goal of a developing a working prototype for performance comparison with conventional systems. 


\begin{abstract}
Separate sensible and latent cooling systems offer significant increases in the overall performance of cooling/dehumidification systems compared with conventional vapor-compression air-conditioning systems. Key to the energy efficiency of such systems is the performance of the heat and mass exchangers that provide sensible cooling and dehumidification. A novel design is proposed for dehumidification applications, deploying metal foam as a substrate coated with solid desiccants. The current report provides some preliminary information regarding the development of the technology and discusses factors such as manufacturing of desiccants, characterization of desiccants, and development of the metal foam heat exchanger. All three aspects provide the necessary infrastructure for further development and validation of the proposed concept.
\end{abstract}

\title{
1. SIGNIFICANCE OF SEPARATE SENSIBLE AND LATENT COOLING SYSTEMS
}

A conventional air-conditioning system manages two kinds of cooling loads, sensible and latent. Sensible cooling is achieved by an evaporator by reducing the temperature of the supply air. During conventional operation, the refrigerant temperature in the evaporator is below the dew point of the supply air, and moisture in the air condenses on the evaporator and therefore reduces the humidity ratio of the delivered air. Thus, the latent heat is removed by the condensation of water vapor in the air.

Theoretically, the flow of the supply air through the evaporator follows a path that consists of horizontal sensible load removal (point A to point B) and latent load removal along the $100 \%$ relative humidity (RH) line from $\mathrm{B}$ to $\mathrm{C}$, as presented in Figure 1. Commonly, the temperature at point $\mathrm{C}$ is too low for thermal comfort; therefore a reheating process is sometimes used that brings the temperature from point $\mathrm{C}$ to the temperature at point $\mathrm{D}$. The reheating process, usually carried out by electric heaters, requires extra energy and increases the total net energy consumption. Hence, reheating reduces the overall performance of the system.

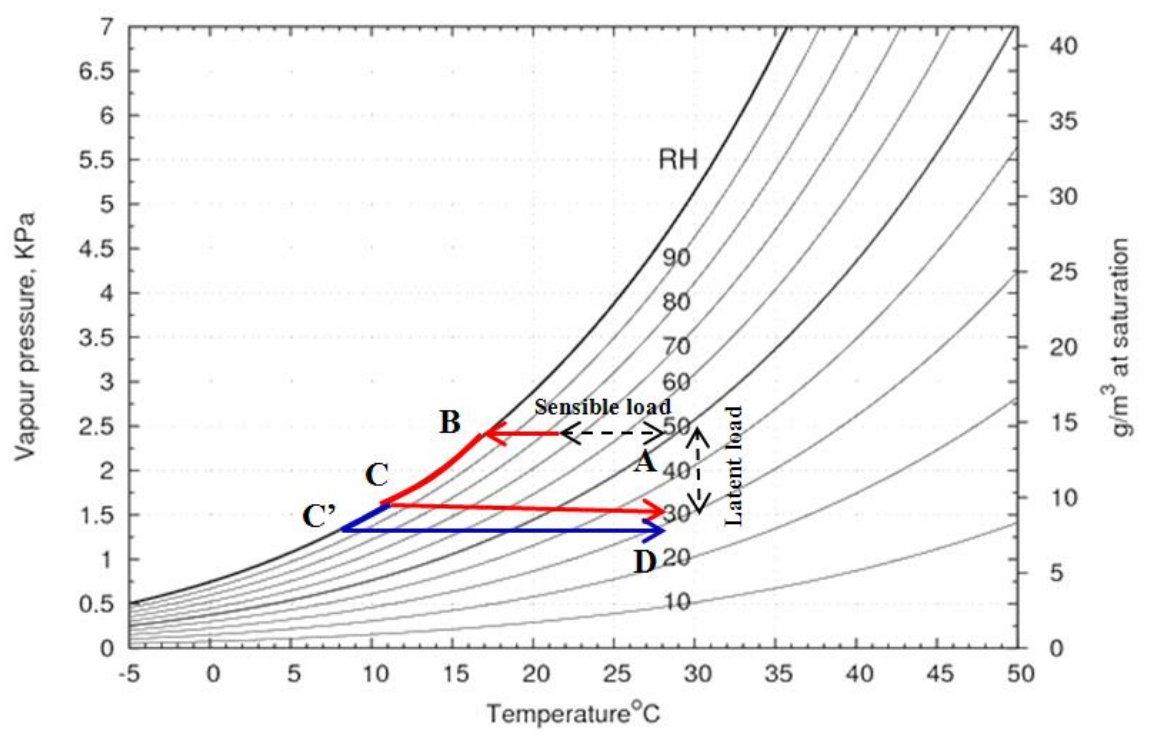

Figure 1. Operation of conventional air conditioning system.

Reheating is required in conventional systems because of the coupled control of sensible and latent cooling. The path from point $\mathrm{B}$ to point $\mathrm{C}$ along the $100 \% \mathrm{RH}$ line reveals that the amount of latent cooling and the amount of sensible cooling are coupled. Hence, removing a certain amount of water vapor requires an 
accompanying ratio of temperature reduction. Therefore, the more latent cooling that takes place, the more likely it is that sensible over-cooling will result. Such a dependent relationship not only increases the cost of operation but also causes a control issue in conventional systems. For example, when there are more people in the building, extra latent cooling (the vertical blue arrow pointing downward) is required. The supply air point moves downward to point $\mathrm{C}$. Meanwhile, an unnecessary amount of sensible cooling has to be added to the room as well. This requires more reheating power input to increase the temperature for thermal comfort and further reduces the performance of the heating, ventilation, and air-conditioning (HVAC) system.

Separate sensible and latent cooling (SSLC) systems are considered a possible alternative to conventional air-conditioning systems. The psychrometric process of an SSLC system is presented in Figure 2. This system consists of one vapor-compression system and one solid desiccant wheel (enthalpy wheel). The vapor-compression system provides only the sensible cooling (point A to point B) required by the conditioned space at both the elevated air temperature leaving the evaporator, and a higher air mass flow rate. The higher air mass flow rate is required to compensate for the reduced enthalpy difference of air across the evaporator and maintain the capacity of sensible cooling. The vapor-compression system operates above the dew point temperature of the supply air and is not required to provide latent cooling. The desiccant wheel, in turn, is used to reduce the water vapor content in the air leaving the sensible evaporator. The dry air from the desiccant wheel mixes with the rest of the air from the evaporator and is delivered to the conditioned space (point D).

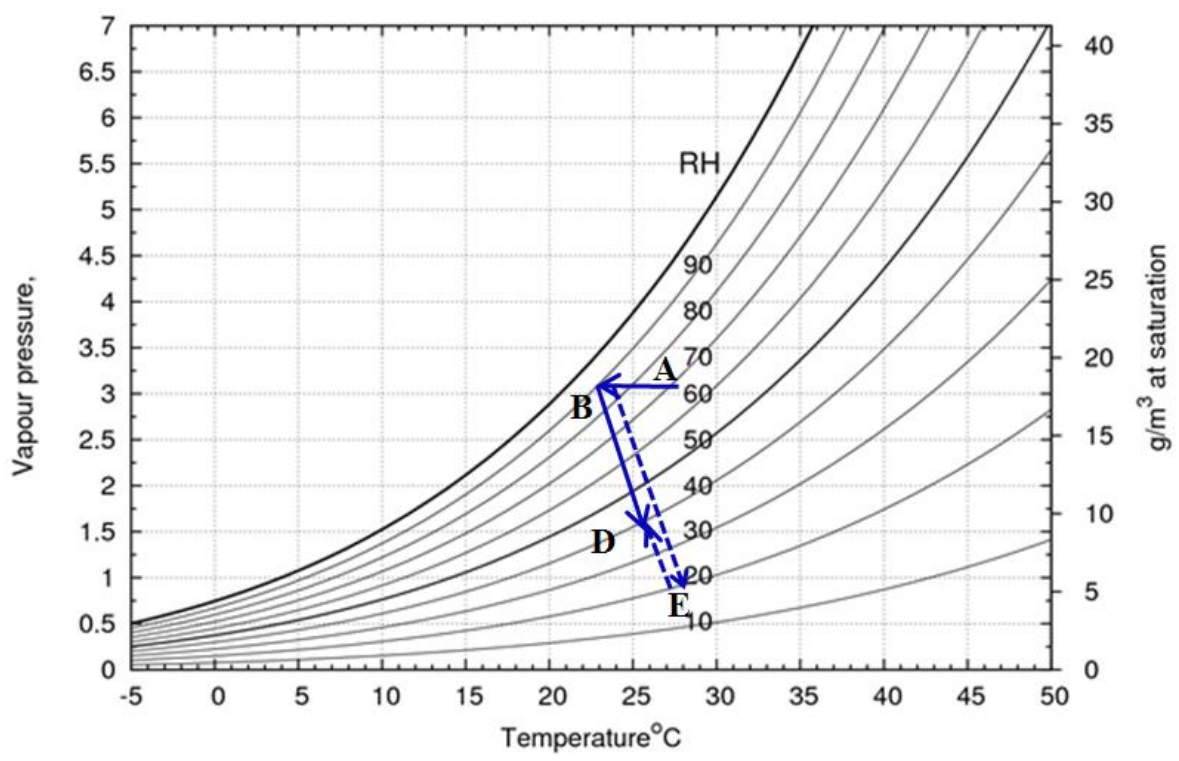

Figure 2. Operation of SSLC system (with enthalpy wheel).

To summarize, SSLC systems have two features that distinguish them from conventional systems. First, since the vapor-compression system used in an SSLC system operates above the dew point temperature, the supply air temperature is thermally comfortable and can be sent to the conditioned room directly. Hence, no reheating is necessary in SSLC systems. Second, because an SSLC system uses a vapor-compression system to provide sensible cooling, any fluctuations in sensible cooling demand can be met simply by changing the capacity of the vapor-compression system. To handle fluctuations in latent cooling demand, the capacity of the desiccant system can be enhanced; for example the rotation speed of the enthalpy wheel can be adjusted to satisfy the latent cooling load. However, note that the loads are still coupled because of the mixing of the air streams, and such processes can be performed only within a limited range of operation. Any change in latent cooling demand change that cannot be satisfied by adjusting the rotation speed of the 
enthalpy wheel will be unmet. Such drawbacks justify the need for a desiccant moisture removal device with more independent load matching and better operational control. Furthermore, although a desiccant wheel is a stand-alone device providing latent cooling, any degree of change in the latent capacity would theoretically lead to the same degree of change in sensible heat generation. Therefore, the vaporcompression system must increase the cooling capacity to cover the extra heat. Thus, the processes of the vapor compression system and those of the desiccant wheel remain linked, and independent treatment of the two sometimes leads to impractical conclusions.

\section{DESCRIPTION OF THE PROPOSED SYSTEM}

Metal foams have a relatively high ratio of surface area to volume and a tortuous structure (Figures 2 and 3 ), making them good candidates for use in compact heat exchangers. Additionally, they are commercially available in a broad range of pore sizes and porosity. Some representative findings regarding the thermal hydraulic performance of metal foams are presented in Section 3.2 of this report. Because of the higher thermal conductivity of the base materials (aluminum and copper), the foams have relatively higher thermal conductivity compared with conventional substrate materials used for enthalpy wheels, such as the plastic honeycomb structure.

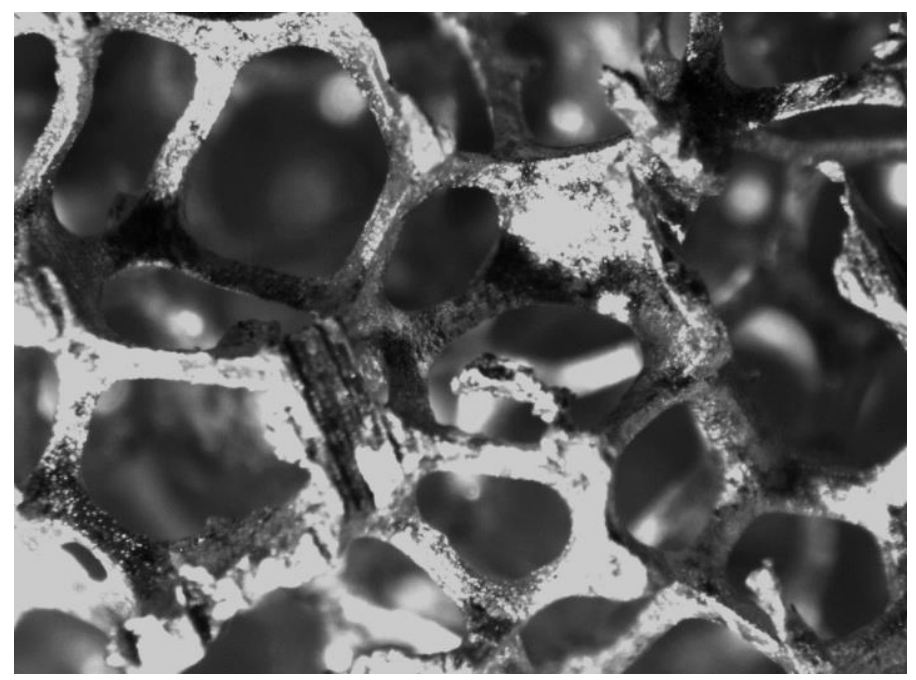

Figure 3. A close-up view of a 10 PPI metal foam cell. 


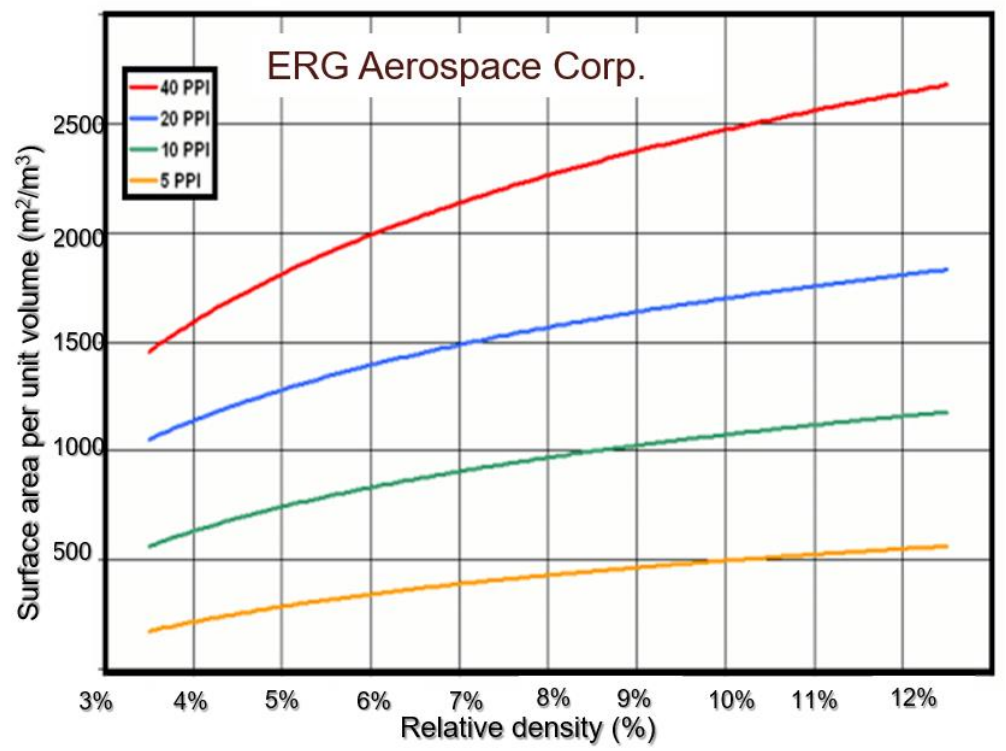

Figure 4. Surface area per unit volume for different metal foams (ERG Aerospace Materials).

Silica aerogel is being used as a solid desiccant in enthalpy wheels, but there has been no serious effort to characterize silica aerogel dehumidification performance and relate it to the micro-structure. Hence, the adsorption/desorption performance of silica aerogels prepared by different methods, has yet to be determined. However, important thermal characteristics of silica aerogels have been extensively reported in the literature, and these materials have been classified as thermal insulations with significantly lower thermal conductance. Thus, although they have been shown to be reasonably good hygroscopic materials, the application of silica aerogels as coatings on mantellic substrates has not been extensively studied. For obvious reasons, any effort to coat a metallic surface (with a conventional surface area) with an aerogel will require a thick coating, which will suppress the advantage of the higher thermal conductivity of the substrate. Perhaps that is the reason metallic substrate materials have not been used in such application as enthalpy wheels - they merely make the system bulky and expensive without providing much benefit.

However, a metal foam is a special type of metallic substrate with an enormously large surface area-tovolume ratio (as shown in Figure 4). Because of the larger surface area, even a relatively thin coating can provide a substantial amount of desiccant in the device, which can potentially meet the capacity requirement. Essentially, a metal foam heat exchanger (MFHX) coated with a thin layer of silica aerogel provides an efficient method of managing the heat produced during moisture adoption and the heat required for desorption by heating and cooling the metal foam fins (substrate) that interact with the coolant flow through the tubes. Figure 5 shows a representative device consisting of metal foam coated with silica aerogel (a macroscopic porous media coated with a microscopic porous media) for dehumidification. There are good reasons to believe such a system can provide more effective humidification/dehumidification as a result of the large surface area of a conductive substrate (metal foams) coated with silica aerogels. 


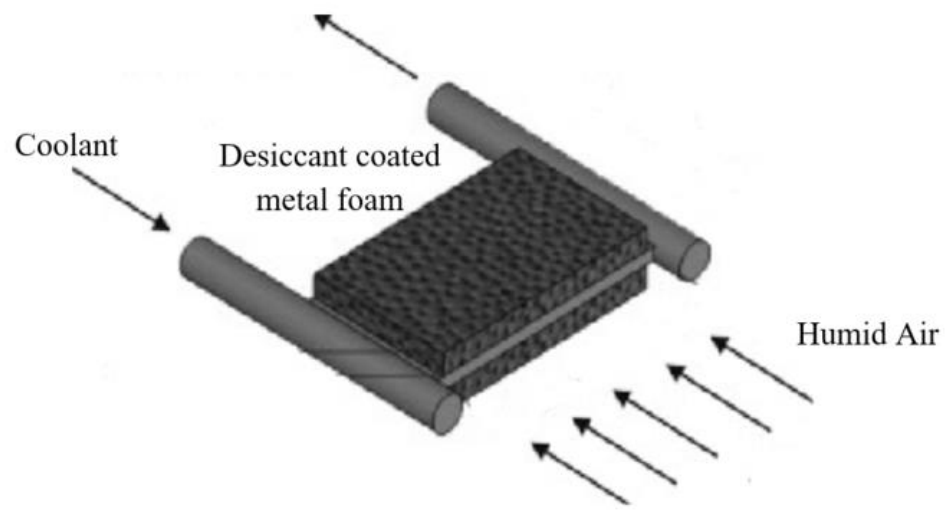

Figure 5. A configuration for a desiccant-coated metal foam dehumidification device.

\section{FEASIBILITY ANALYSIS FOR PROPOSED SYSTEM}

To successfully develop and validate the proposed system, several critical tasks must be accomplished to ensure its practicality. This section describes some developments in this regard and discusses and elaborates upon aspects of the research such as the development of MFHXs and manufacturing and characterization of the silica aerogels.

\subsection{DEVELOPMENT OF METAL FOAM HEAT EXCHANGERS}

Metal foams are porous metallic structures; and despite their high tensile/compression strength and toughness, machining such materials is not an easy task. Because of their tortuous structure, operations such drilling and cutting require special care. Figure 6 presents some representative heat exchanger samples prepared using conventional tooling. Two principal round tube configurations were considered: (1) a through-hole approach in which several tubes pass through the metal foam block and are bonded using thermally conductive epoxy and (2) a configuration in which the tubes are placed in grooves on the surface of the foam and bonded using a thermal epoxy. Although some portion of the tube is not in contact with the foam in the second configuration, it is relatively easy to manufacture, as the drilling process can be avoided. Regardless of the configuration, it is expected that the relative difference in the performance will be minimal. One additional feature to consider is the placement of manifolds, either a single-pass (manifolds on opposites sides) or a two-pass (manifolds on the same side) configuration.
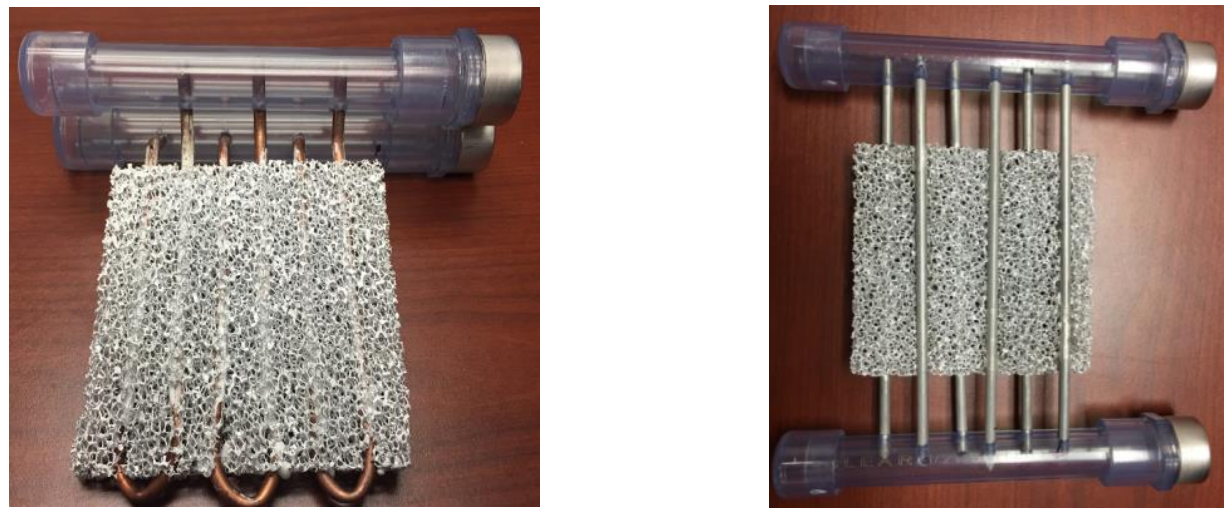

Figure 6. Metal foam heat exchanger (constructed in-house). 


\subsection{EXISTING KNOWLEDGE ABOUT THE PERFORMANCE OF MFHXs}

Only limited information available for MFHX performance in HVAC and refrigeration applications (Han et al. 2012). One recent study concluded that MFHXs have a significantly higher heat transfer rate than louver-fin heat exchangers (Nawaz et al. 2017). This remarkable improvement in thermal performance mitigates the associated higher pressure drop. Figure 7 presents the air-side thermal performance of an MFHX for a comparable pressure drop (fan power). This analysis is based on dry operation; it can be seen that, under dehumidifying conditions, the performance will be different because condensate drainage may be an issue. Furthermore, the heat exchanger configuration is different-metal foam fins were stacked between microchannel tubes to form the heat exchangers.

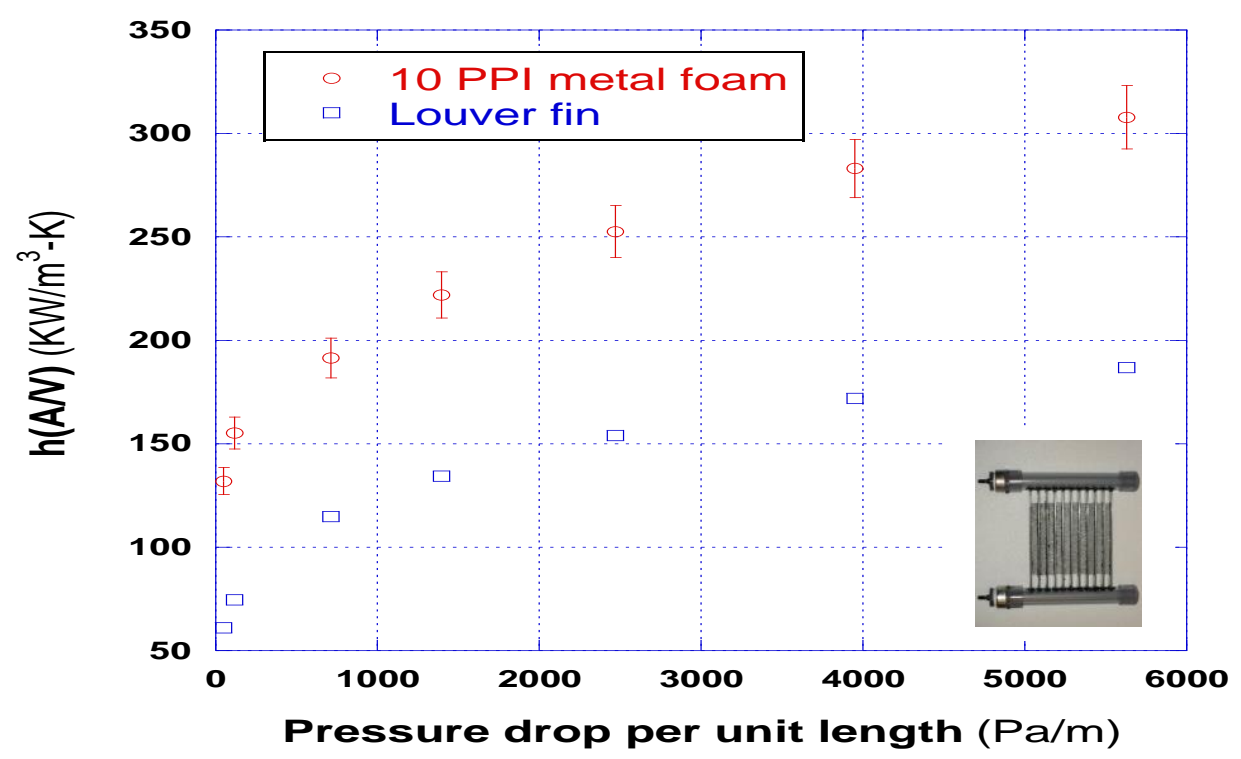

Figure 7. Thermal-hydraulic performance of metal foam heat exchangers under dry operating conditions.

\subsection{MANUFACTURING OF SILICA AEROGELS}

Many different preparation methods are available for manufacturing silica aerogels, with hydrolysis and condensation processes occurring in one or two steps. Most silica aerogels are prepared using silicon alkoxide precursors. Generally, tetramethyl orthosilicate (TMOS, $\left.\mathrm{Si}\left[\mathrm{OCH}_{3}\right]_{4}\right)$ and tetraethyl orthosilicate $\left(\mathrm{TEOS}, \mathrm{Si}\left[\mathrm{OCH}_{2} \mathrm{CH}_{3}\right]_{4}\right)$ are used for this purpose. However, many other alkoxides, containing one or more organic functional groups (alcohols, ethers, aldehydes), can be used to impart different physical properties to the gel. For the current study, the wet gels were formed by TMOS. The reaction is presented in Eq. (1):

$$
\mathrm{Si}\left(\mathrm{OCH}_{3}\right)_{4} \text { (Liq.) }+2 \mathrm{H}_{2} \mathrm{O} \text { (Liq.) } \rightarrow \mathrm{SiO}_{2}(\text { Solid })+4 \mathrm{HOCH}_{3} \text { (Liq.) . }
$$

The kinetics of the above reaction render it impracticably slow at room conditions, often requiring several days to complete. For this reason, acid or base catalysts are added to make the process faster. The amount and type of catalyst used is critical to the microstructural and physical properties of the silica aerogels. Acid catalysts can be any protic acid (containing hydrogen), such as $\mathrm{HCl}$ or $\mathrm{HF}$. Basic catalysis usually uses ammonia, ammonium hydroxide, or ammonium fluoride. High-resolution scanning electron microscopy (SEM) images show that silica aerogels consist of small particles that are generally spherical or egg-shaped (Figure 8). 


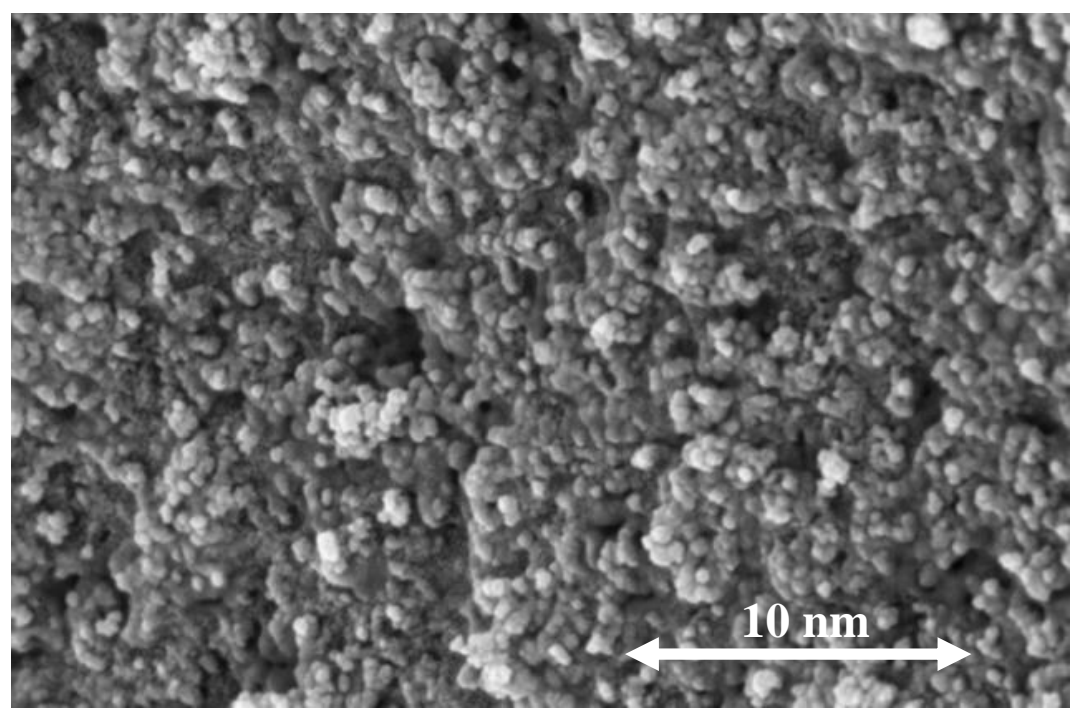

Figure 8. Microstructure of silica aerogel prepared by sol-gel process.

The final, and most important, step in making silica aerogels is drying to remove the liquid within the gel, leaving only the linked silica network. The wet gel can be dried either by evaporation or by supercritical drying with $\mathrm{CO}_{2}$ or alcohols. It was observed in the current study that when the gels are dried by evaporation, the resulting glass-like material (xerogel) cracks and the porous structure is not durable (Figure 9a). Instead of evaporation, if a sample is dried under supercritical conditions, the effects of surface tension, resulting in the cracking of the coating, can be eliminated (Figure 9b). In Figure 9, both specimens were prepared with the same type of gel.
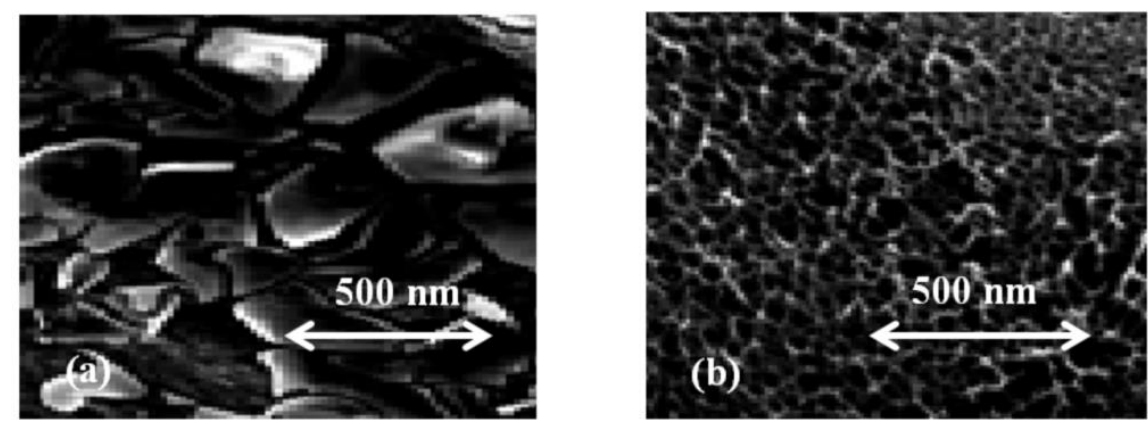

Figure 9. SEM images of silica aerogel coated metal foam ligaments dried (a) by evaporation (b) supercritically $\left(\mathrm{CO}_{2}\right)$.

The supercritical drying process is performed by venting ethanol or methanol above their critical point $\left(241^{\circ} \mathrm{C}, 6300 \mathrm{kPa}\right.$ for ethanol and $240^{\circ} \mathrm{C}, 7850 \mathrm{kPa}$ for methanol). It can take up to 24 hours, depending on the sample size. A better option is performing the process at relatively lower temperature and pressure by prior solvent exchange with $\mathrm{CO}_{2}$ followed by supercritical venting. Another advantage of supercritical drying using $\mathrm{CO}_{2}$ is that less time is required for completion (a third of the time required for the normal process using ethanol or methanol). To perform the process, the wet gel was placed in an autoclave filled with ethanol/methanol. The system was pressurized to $5200-5900 \mathrm{kPa}$ with $\mathrm{CO}_{2}$ and cooled to $5-10^{\circ} \mathrm{C}$. Liquid $\mathrm{CO}_{2}$ was then flushed through the vessel until all the methanol had been removed from the vessel and from within the gel. When the gel had a negligible amount of methanol in its structure, the vessel was heated to a temperature above the critical temperature of $\mathrm{CO}_{2}\left(31^{\circ} \mathrm{C}\right)$. As the temperature was increased, the pressure of the system was increased as well. $\mathrm{CO}_{2}$ was continuously added to maintain a pressure 
slightly above the critical pressure of $\mathrm{CO}_{2}(7240 \mathrm{wkPa})$. The system was held under these conditions for about 2 hours (the time can vary based on the size of the sample), followed by the slow, controlled release of $\mathrm{CO}_{2}$ until the system reached ambient pressure. The process for the preparation of silica aerogel is summarized in the flow chart given in Figure 10.

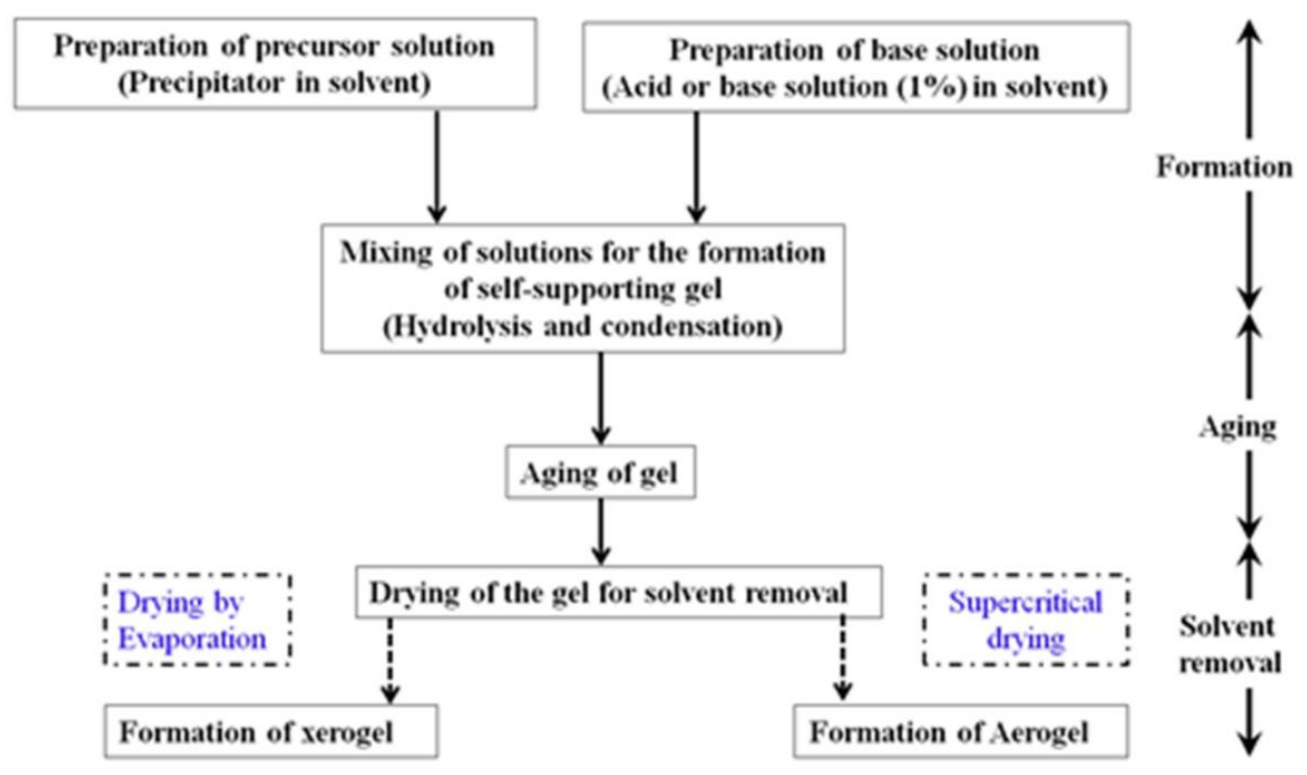

Figure 10. Manufacturing of silica aerogels (adapted from Brinker and Scherer 1990).

\subsection{CHARACTERIZATION OF SILICA AEROGELS}

It is critical to evaluate the performance of desiccants by establishing the surface area that directly relates to the steady-state and transient properties of such materials. Additionally, microscopic analysis of the structure can provide important information regarding the porosity. This section covers both topics. First a BET surface area analysis is presented and compared with values for some conventional desiccants to elaborate the significance of the selection of silica aerogels as desiccants. Later, an SEM analysis of the microstructure of the aerogels is discussed.

Thermal gravimetric analysis (TGA) is often conducted to establish the surface area of a porous structure with micro-, nano-, and mesoporous materials. Commonly, nitrogen or carbon dioxide gases are used for such an analysis, in which the adsorption and desorption behavior of the gas is analyzed at a range of partial pressure conditions. The resulting isotherms are used to estimate the BET surface area. Table 1 summarizes the surface area per unit of mass for three desiccants, and Figures 11-13 present the complete isotherms for nitrogen gas adsorption for the three materials.

Table 1. Surface area per unit mass for desiccant

\begin{tabular}{|l|c|}
\hline \multicolumn{1}{|c|}{ Material } & Surface area $\left(\mathbf{m}^{\mathbf{2}}\right.$ per gram) \\
\hline Silica aerogel (ammonium hydroxide) & 1035 \\
\hline Zeolite 13 X & 493 \\
\hline Drierite anhydrous calcium sulphate & 12.1 \\
\hline
\end{tabular}




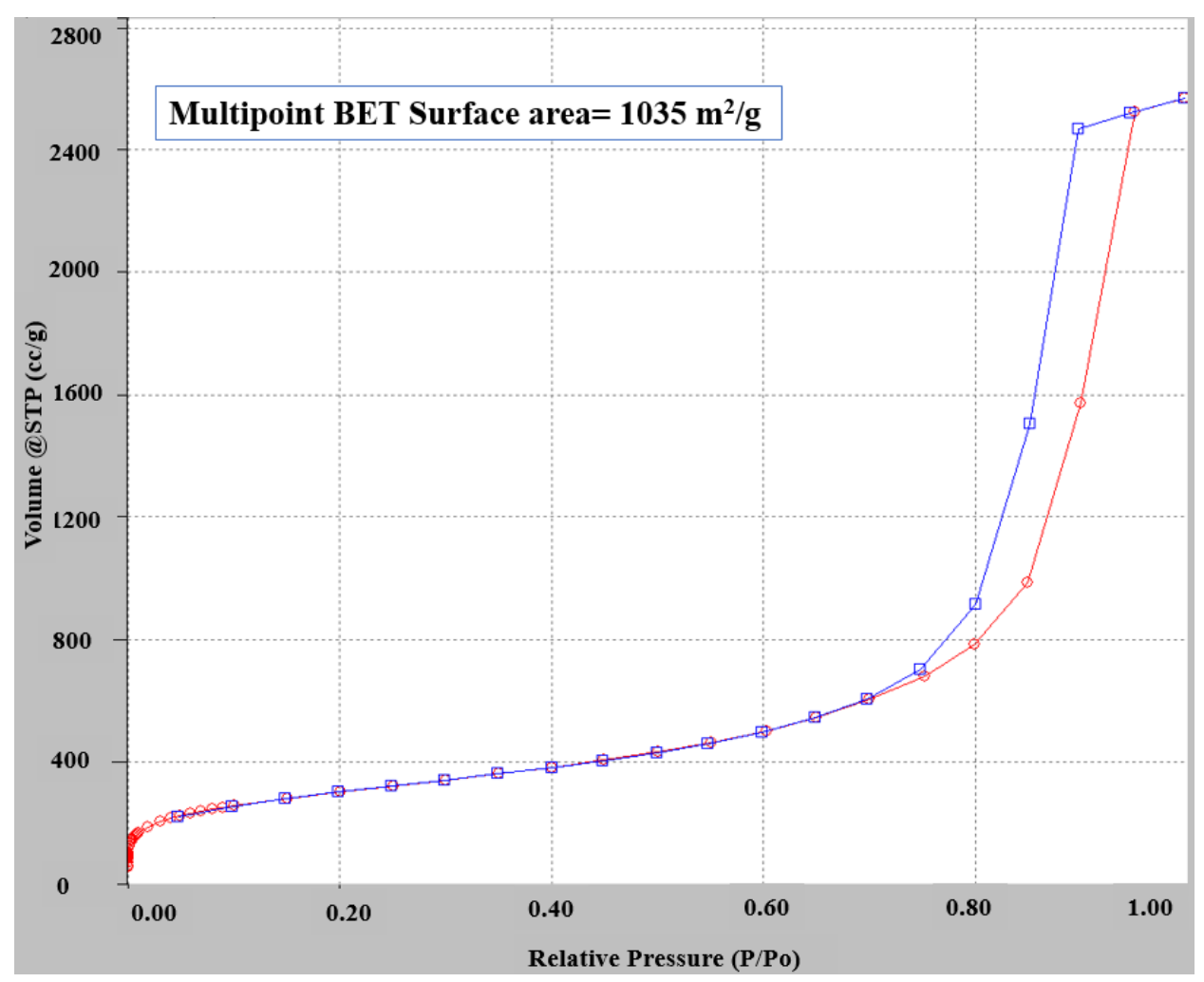

Figure 11. Nitrogen adsorption/desorption for silica aerogels.

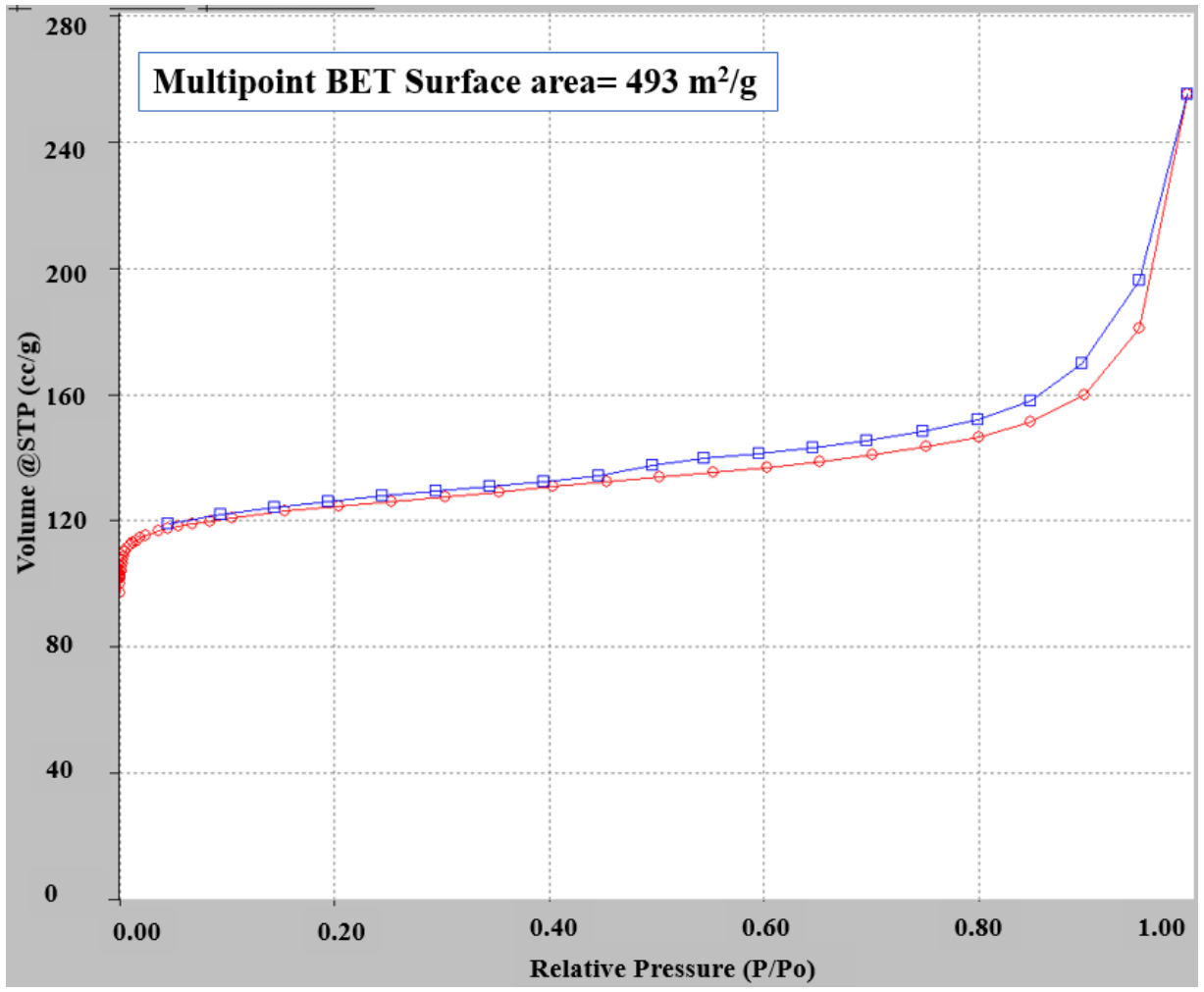

Figure 12. Nitrogen adsorption/desorption for Zeolite 13X. 


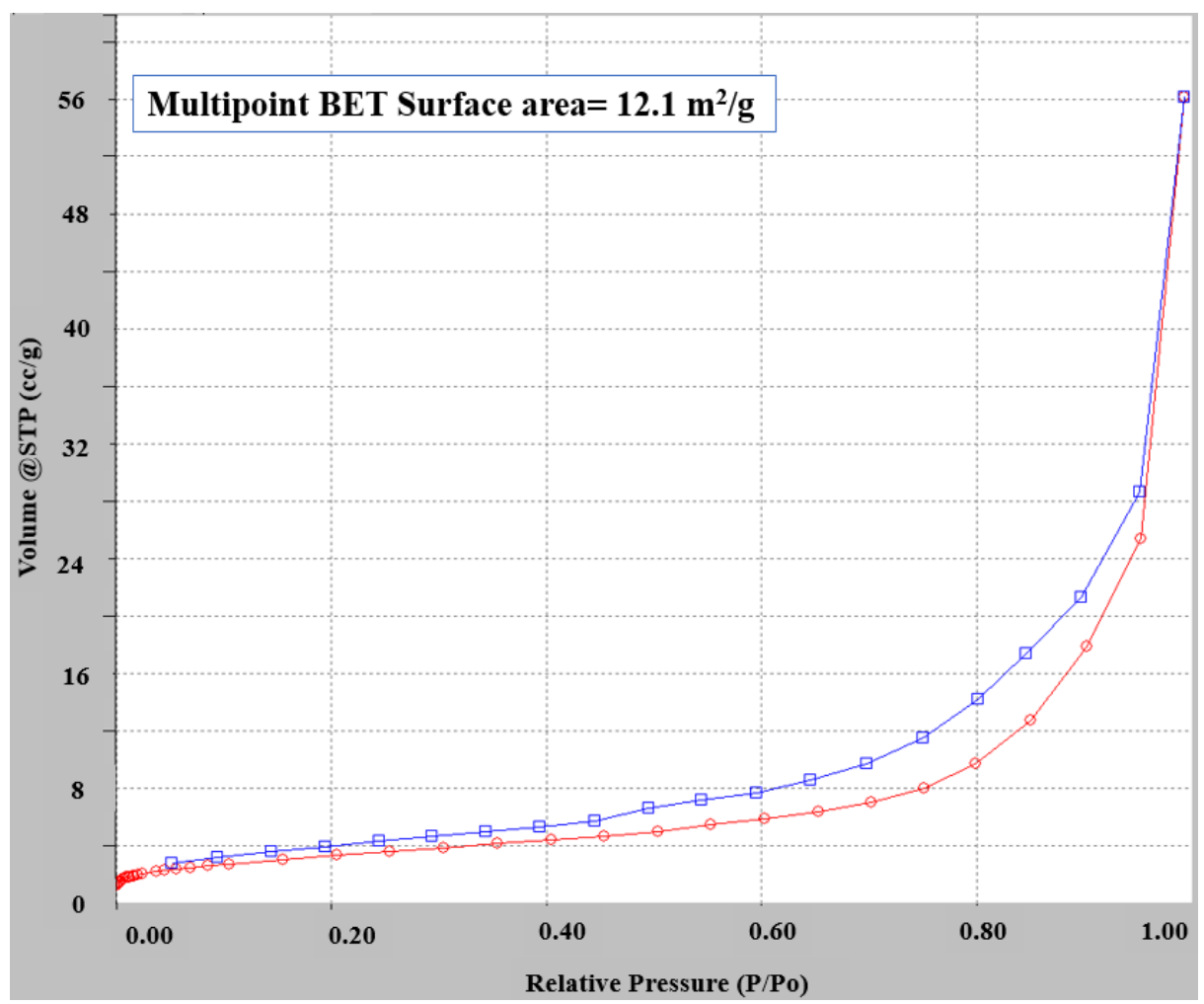

Figure 13. Nitrogen adsorption/desorption for drierite $\left(\mathrm{CaSO}_{4}\right)$.

It can be inferred from the above experimental data that silica aerogels have a significantly larger surface area-to-volume (or mass) ratio than the other desiccants. The difference is due to the highly porous structure with pore sizes of less than a micron. It is important to note that although nitrogen adsorption/desorption behavior is studied in the current analysis, it is expected that a similar trend can be observed for moisture vapor adsorption. To assess whether that is the case, a dynamic vapor sorption facility was procured which will be used to develop steady-state moisture isotherms. The findings provided by this facility will help us determine the mass diffusivity of water vapor, as well as the capacity for a variety of operating conditions observed in field.

SEM analysis was conducted simultaneously to analyze the structure and to determine the impact of the silica aerogel synthesis process. Figures 14 and 15 show SEM images of two aerogel samples prepared using different catalysts. It is obvious from the analysis that the catalyst plays an important role in the process, and the microstructure is a strong function of the catalyst used in the process. A sample prepared using hydrofluoric acid as the catalyst has relatively small pore sizes; whereas in the sample prepared using ammonium hydroxide, the pore sizes are relatively large. These structural differences will lead to remarkably different moisture adsorption/desorption characteristics. 


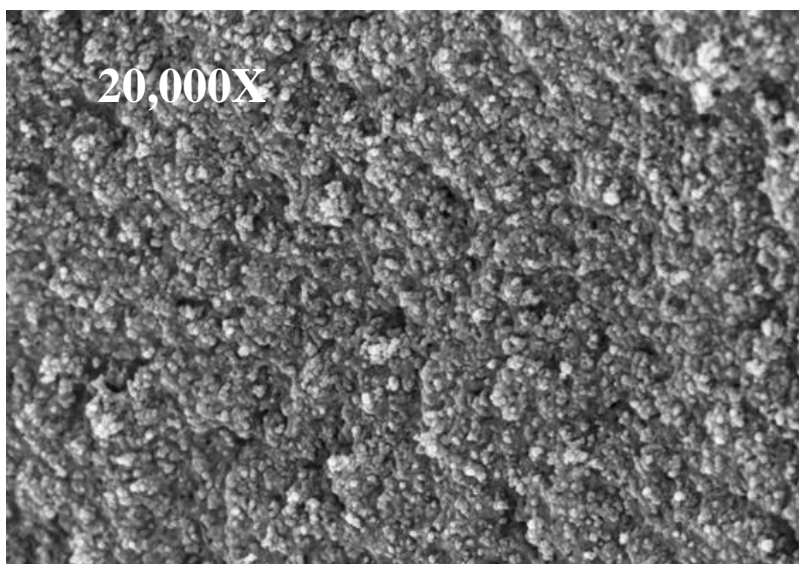

Figure 14. SEM image of a silica aerogel prepared using ammonium hydroxide.

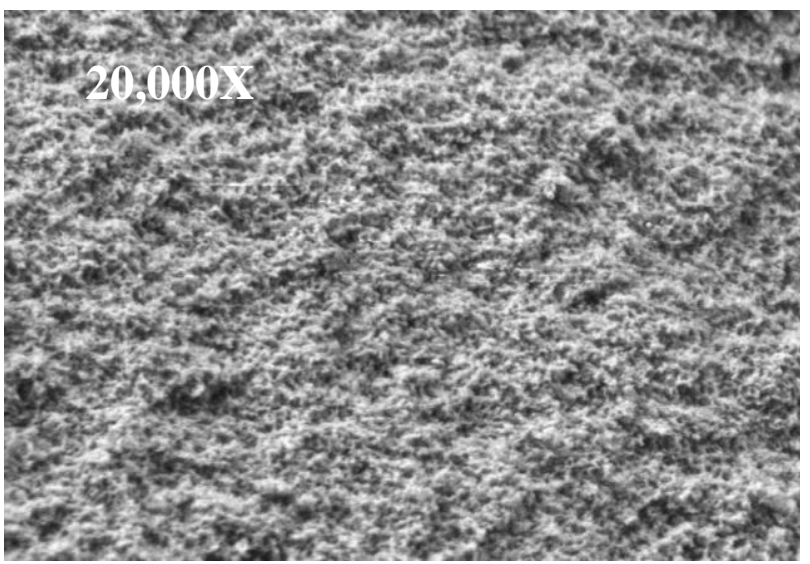

Figure 15. SEM image of a silica aerogel prepared using hydrofluoric acid.

\section{FUTURE TASKS}

Based on the progress during phase 1 of the project, the following are some key future milestones for developing a working prototype.

1. Thermal hydraulic performance of MFHX under dehumidifying conditions: Appropriately adjusting the conditions can cause the moisture in the air to condense on the heat exchanger surface. A series of wind-tunnel experiments are planned in which the heat transfer rate (sensible and latent) and associated pressure drop will be measured to accurately assess performance.

2. Moisture adsorption/desorption characterization of desiccants: Nitrogen gas adsorption has been used so far to establish the BET surface area of desiccants (silica aerogels). As a next step, more suitable experiments will be conducted using the dynamic vapor sorption apparatus to analyze the transient and steady-state adsorption/desorption behavior of a range of desiccants that could be deployed as coatings (including silica aerogels, activated carbon, and zeolites). In those experiments, the moisture adsorption/desorption behavior will be analyzed at various operating temperatures and relative humidity levels.

3. Moisture adsorption/desorption characterization of desiccant coated substrates: Previous studies have shown that the performance of desiccants deployed as coatings can be significantly different from the performance when they are used in bulk form (e.g., as grains or powder). This task will establish the impact of the addition of a metallic substrate material to the application.

4. Development and testing of prototype: At the conclusion of tasks 1-3, a working prototype (desiccant-coated heat and mass exchangers) of conventional geometry (i.e., flat plate fins) and compact geometry (metal foam fins) will be analyzed, and the performance will be compared with that of conventional approaches (vapor-compression cycle for dehumidification and enthalpy wheel). 


\section{CONCLUSIONS}

Based on the findings described in this report, it can be concluded that an MFHX can serve as a substrate material for the proposed configuration. Among various desiccants, silica aerogels have significantly higher surface area per unit of mass compared with other hygroscopic materials, which indicates better hygroscopic properties. The SEM images conclude that the manufacturing process can considerably impact the microstructure of the silica aerogels.

\section{ORNL RECOMMENDATIONS}

Based on the findings described, ORNL recommends that the project pass the preliminary scoping analysis and proceed to the next tasks as described. Along with further development of the technology, an appropriate industry participant will be contacted for system-level validation through a Cooperative Research and Development Agreement.

\section{REFERENCES}

ASHRAE 2017. ASHRAE Handbook—Fundamentals, ASHRAE, Atlanta.

Y. Hwang, O. Kuwabara, J. Ling, R. Ratemeter 2010. "Enhancement of the separate sensible and latent cooling air-conditioning systems," presented at the International Refrigeration and Air Conditioning Conference, Purdue University, July 10-15, 2010.

ERG Materials and Aerospace 2017. http://www.ergaerospace.com/index.html

C. J. Brinker and G. W. Scherer 1990. Sol-Gel Science, The Physics and Chemistry of Sol-Gel Processing, Academic Press Inc, Elsevier.

K. Nawaz, J. Bock, Z. Dai, and A. Jacobi 2017. "Thermal-hydraulic performance of metal foam heat exchangers under dry operating conditions," Applied Thermal Engineering 119(5), 222-232. 